\title{
Critical Mass Flowrate at the Firepoint of Plastics
}

\author{
H. E. THOMSON and D. D. DRYSDALE \\ Unit of Fire Safety Engineering \\ University of Edinburgh \\ King's Buildings \\ Edinburgh, EH9 3JL, Scotland, UK
}

\section{ABSTRACT}

The critical mass flux at the firepoint for eight common thermoplastics (including two fire retarded modifications) has been measured by exposing horizontal samples to irradiance levels in the range $12-35 \mathrm{~kW} / \mathrm{m}^{2}$ and monitoring their weight loss. The results are significantly lower than values reported elsewhere: this may be attributed to differences in the convective heat transfer coefficient at the surface.

\section{INTRODUCTION}

Although the term "flammability" is often applied to combustible solids, it has no scientific definition in this context. It is used loosely to cover several aspects of fire behaviour, from ease of ignition to rate of heat release, but none of these can be quantified in terms of the properties of the material per se. It is the purpose of this paper to examine some of the factors which contribute to the ease with which plastics can be ignited from a pilot and to provide data which may be used to quantify this and other aspects of "flammability".

In an earlier paper (1), data on the firepoint temperatures of $s i x$ common thermoplastics were presented. This work was carried out to test the common assumption that the condition for piloted ignition could be modelled as a critical surface temperature. This has been made in simple ignition models in which the material is treated as an inert solid, e.g. $(2,3)$. "Ease of ignition" can be shown to depend on the rate at which the exposed surface responds to an imposed heat flux, which in turn depends on the thickness and thermal properties of the material $(2,4)$. For radiative heating, the radiant distribution of the source and the absorption characteristics of the "receiver" also need to be taken into account $(1,5)$.

However, when examining the ignition process at this level of detail, it is no longer possible to ignore decomposition of the fuel. If a model of the ignition process is to be developed in order to improve (inter alia) the interpretation of the results of small scale tests such as the ISO Ignitability rest (6), then information on the effect of the decomposition of the fuel on the ignition process is essential. 
Bamford et al. (7) first suggested the existence of a minimum critical rate of production of fuel vapours at the point at which $a$ combustible solid could be ignited, but there have been few attempts tc test this hypothesis $(8,9)$. Values that have been quoted tend to be scattered and, generally, there is an insufficient data base for any comparative study to be made. The work described in this paper was undertaken to help remedy this situation and provide the opportunity tc test the firepoint equation proposed by Rasbash $(10,11)$.

\section{EXPERTMENTAL}

An apparatus was constructed to allow the mass loss of a sample of material to be monitored as it was subjected to radiant heating (Figure 1). The principle component of the rig was a Sartorius top loading balance (Model L610) (I) which was used to monitor the weight of $\varepsilon$ horizontal sample continuously, providing an analogue output to a per chart recorder. A lightweight aluminium tripod $(\mathrm{J})$ which fitted over the pan of the balance was constructed to support a glass rod ( $\mathrm{K}$ ) or which the sample mounting platform was attached. The output voltage from the balance could be offset to allow the initial dead weight of the platform, tripod and sample to be tared at the start of each experiment. A conical heater (C), identical to that used in the IsO Ignitability Test (6) acted as the source of radiation. The heat flux was varied by maintaining the heater at a constant temperature and varying its height above the sample.

It should be noted that the present rig differed significantly from that used by Deepak and Drysdale ( 9 ), in which the sample was containec within a vertical, water cooled chimney (150mm i.d.). This geometry was similar to Tewarson's apparatus (12) to allow the composition of the atmosphere at the sample surface to be varied (11).

Foil wrapped samples $(65 \times 65 \times 6 \mathrm{~mm})$ backed by a piece of "Supalux" were placed in a stainless steel holder which exposed a circular area of surface $60 \mathrm{~mm}$ in diameter, and positioned centrally on the platform. A heat shield was placed between the heater and the sample until the heater had achieved equilibrium. The output was monitored by a water-cooled Gardon-type heat flux meter set to one side of the sample; this had been calibrated against a heat flux meter located in the sample position.

Preliminary experiments produced mass loss curves with unacceptable levels of noise, apparently caused by external vibration and buoyancyinduced air movements in the vicinity of the sample. The quality of the traces was much improved by surrounding the sample platform and holder with a "collar" made from Supalux, the upper surface of which was flush with the surface of the sample. In addition, the surface was shielded from draughts by a cylinder, $50 \mathrm{~mm}$ high and $100 \mathrm{~mm}$ in diameter, formed from $1 \mathrm{~mm}$ thick steel sheet (Figure 2). A limited number of experiments were repeated with neither the collar nor the shielding present to ascertain their effect.

The fuel volatiles were ignited by means of a spark discharge, applied approximately $5 \mathrm{~mm}$ above the sample surface. The discharge was more than adequate to ignite even a flammable mixture close to the lower flammability limit. In a few experiments, a small hydrogen diffusion flame was used as the pilot: the flame, which burned at the end of a $2 \mathrm{~mm}$ i.d. copper pipe, was passed above the sample surface at regular 
intervals, similar to the procedure recommended in the Cleveland open Cup Test for determining the open cup flashpoint of flammable liquids (13).

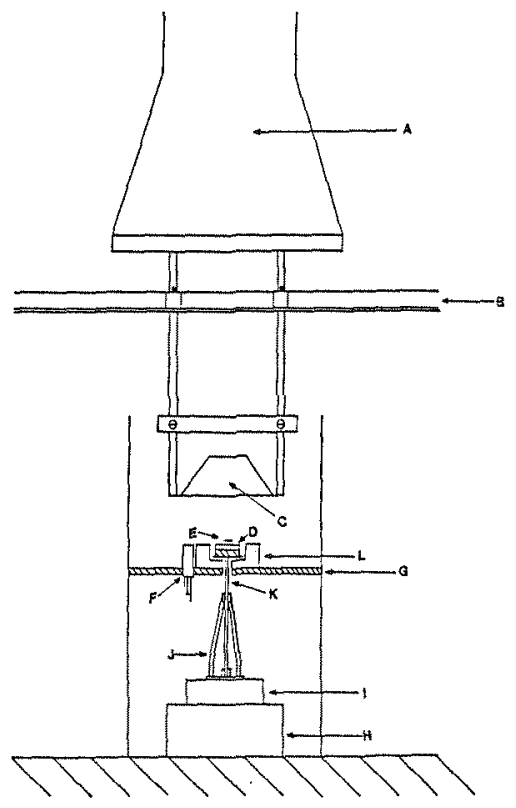

Figure 1. Section through the apparatus. A, to extract; $B$, horizontal support bar; C, conical heater; D, Sample; E, spark discharge; $F$, water-cooled radiant heat flux meter; $G$, Supalux platform; $H, \quad$ concrete plinth; I, Sartorius balance; J, Aluminium tripod; K, glass rod; L, Supalux "collar" (see Figure 2).

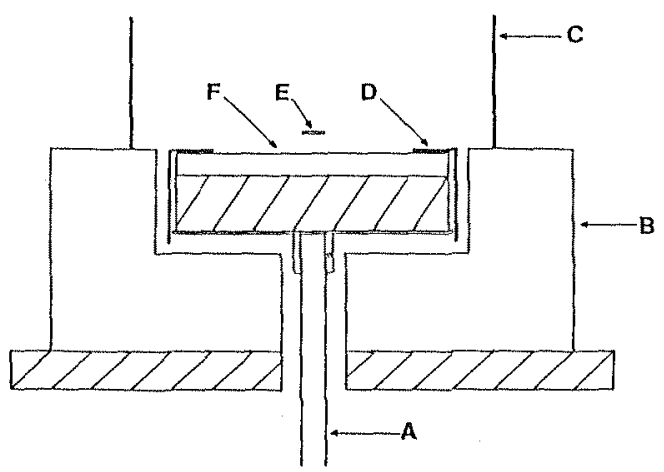

-igure 2 Detail of sample holder and collar, from Figure 1. A, glass rod; B, Supalux "collar"; C, Steel. cylinder; D, sample holder; E, Iocation of spark; F, sample surface.

The critical flow rate of the volatiles at the firepoint was derived from the limiting slope of the mass loss curve at the instant that flame first became established at the surface and was converted to a mass flux. In most of the experiments, the onset of flashing was recorded so that it was possible to calculate the mass flux corresponding to the flashpoint $\left(\dot{m}^{\prime \prime}{ }_{\mathrm{fl}}\right)$. 
Critical mass fluxes were determined for the materials listed in Table 1. Results for polyethylene at the lower heat fluxes were not reproducible and had to be discarded: at the longer heating times, a layer of char forms at the surface and prevents uniform release of volatiles.

Table 1. Identification of Materials

\begin{tabular}{lll} 
Material & Identifier & Source \\
\hline $\begin{array}{l}\text { Polymethylmethacrylate } \\
\text { ("Perspex"): cast } \\
\text { acrylic sheet. }\end{array}$ & PX & $\begin{array}{l}\text { Imperial Chemical. } \\
\text { Industries (ICI). }\end{array}$ \\
$\begin{array}{l}\text { Polymethylmethacrylate } \\
\text { ("Finnacryl"): cast } \\
\text { acrylic sheet. }\end{array}$ & FINN & Lohja Co. of Finland. \\
$\begin{array}{l}\text { Fire retarded poly- } \\
\text { methylmethacrylate: cast } \\
\text { acrylic sheet. }\end{array}$ & FRPX & \\
$\begin{array}{l}\text { Polyoxymethylene } \\
\text { ("Polyacetal"). }\end{array}$ & & Imperial Chemical \\
$\begin{array}{l}\text { Polyethylene } \\
\text { Polypropylene }\end{array}$ & POM & Dupont Ltd. \\
$\begin{array}{l}\text { Fire retarded } \\
\text { polypropylene } \\
\text { Polystyrene }\end{array}$ & PE & Courtaulds Acetate PLC \\
\hline
\end{tabular}

\section{RESULTS}

Results were obtained for the mass flux at the flashpoint for six of the materials, and for the critical mass flux at the firepoint for all eight. The results are presented in Table 2: they were all obtained with the configuration described in Figure 2, using the spark discharge. Additional experiments were carried out on FINN using a small hydrogen diffusion flame as the ignition source to check if there was any dependence on the nature of the source: these results are included in Table 2. In a further series of tests, the configuration around the sample was altered and measurements of $\dot{m}^{\prime \prime}$ obtained in the absence of the surrounding collar and draught shield. This arrangement was closer to that of Tewarson (12) and Deepais and Drysdale (9): this result is included in Table 2 . 


\begin{tabular}{|c|c|c|c|}
\hline $\begin{array}{l}\text { Radiant flux } \\
\left(\mathrm{kW} / \mathrm{m}^{2}\right)\end{array}$ & $\begin{array}{c}\dot{\mathrm{m}}^{\prime \prime}{ }_{\mathrm{cr}} \\
\left(\mathrm{g} / \mathrm{m}^{2}, \mathrm{~s}\right)\end{array}$ & $\underset{i g}{t_{i g}}$ & $\begin{array}{c}\dot{\mathrm{m}}_{\mathrm{fl}}^{\prime \prime} \\
\left(\mathrm{g} / \mathrm{m}^{2} . \mathrm{s}\right)\end{array}$ \\
\hline
\end{tabular}

Polymethylmethacrylate $(\mathrm{PX})\left(\mathrm{T}_{\mathrm{ig}}=31.00 \mathrm{C}\right)^{2}$

$\begin{array}{llrrrr}13 & 1.90(0.14) & 287 & (1.7) & 0.96 & 2.0 \\ 19 & 1.96(0.11) & 127 & (4) & 0.95 & 2.1 \\ 25 & 1.87(0.15) & 58 & (5) & 0.99 & 1.9 \\ 33 & 2.04(0.08) & 30 & (2) & - & -\end{array}$

Polymethylmethacrylate (FINN) $\left(\mathrm{T}_{\text {ig }}=309^{\circ} \mathrm{C}\right.$ )

$\begin{array}{lrrrrrr}13 & 1.95(0.13) & 328(16) & 0.88(0.08) & 2.2 \\ 19 & 2.05(0.09) & 167(1.4) & 1.00(0.11) & 2.5 \\ 25 & 2.15(0.18) & 84(6) & 0.98(0.09) & 2.2 \\ 33 & (2.06(0.18) & 81 & (5))^{3} & - & & - \\ & 1.92(0.19) & 42(2) & - & & -\end{array}$

Fire retarded polymethylmethacrylate (FRPX)

$\begin{array}{llllll}19 & 4.48(0.37) & 352(23) & 2.09(0.07) & 2.1 \\ 25 & 4.32(0.33) & 194(1.3) & 1.37(0.12) & 3.2 \\ 33 & 5.19(0.40) & 89(4) & 1.87(0.20) & 1.9\end{array}$

Polyoxymethylene $(\mathrm{POM}) \mathrm{T}_{\mathrm{ig}}=281{ }^{\circ} \mathrm{C}$ )

$\begin{array}{lrrrrr}13 & 1.83(0.16) & 573(34) & 0.82 & 2.2 \\ 19 & 1.71(0.12) & 275(14) & 0.85 & 2.0 \\ 25 & 1.64(0.06) & 143(4) & 0.90 & 1.8 \\ & (1.89(0.19) & 160(6))^{4} & - & - \\ 33 & 1.73(0.10) & 84(3) & - & -\end{array}$

Polyethylene $(\mathrm{PE})^{5}\left(\mathrm{~T}_{\text {ig }}=363^{\circ} \mathrm{C}\right)$

$\begin{array}{rrrr}25 & 1.24 & (0.25) & 172(11) \\ 33 & 1.38 & (0.23) & 90(6)\end{array}$

Polypropylene $(\mathrm{PP})\left(\mathrm{T}_{\text {ig }}=334^{\circ} \mathrm{C}\right)$

$\begin{array}{rrrrrr}13 & 1.03(0.06) & 442(21) & 0.54 & 1.9 \\ 19 & 1.12(0.08) & 172(13) & 0.62 & 1.8 \\ 25 & 1.10(0.11) & 91(7) & 0.62 & 1.8 \\ 33 & 1.20(0.08) & 57(5) & 0.62 & 1.9\end{array}$

Fire retarded polypropylene (FRPP)
25
$2.34(0.22)$
$285(12)$
33
$3.58(0.34)$
$90 \quad(7)$

Polystyrene (PS) $\left(\mathrm{T}_{\text {ig }}=366^{\circ} \mathrm{C}\right)$

$\begin{array}{llrrrr}13 & 0.93(0.05) & 610(38) & 0.49 & 1.9 \\ 19 & 1.01(0.08) & 209(17) & 0.52 & 2.0 \\ 25 & 1.07(0.06) & 120(5) & 0.56 & 1.9 \\ 33 & 0.91(0.04) & 74(3) & 0.56 & 1.6\end{array}$

1. Figures in brackets are standard deviations.

2. Values of $T$ from (1): these refer to the range $17-40 \mathrm{~kW} / \mathrm{m}^{2}$. Note that the value of $\mathrm{T}$, for $\mathrm{PX}$ was found to be $300^{\circ} \mathrm{C}$ at $14 \mathrm{~kW} / \mathrm{m}^{2}$ (1).

3. Ignition source: hydgogen diffusion flame.

4. Measurements carried out in the absence of the collar and shield.

5. The mass loss curves for PE were irregular and it proved difficult to extract the necessary data from the recordings. 
A series of experiments carried out with FINN showed that the value obtained for $\dot{m}^{\prime \prime}$ is independent of the nature of the ignition sourct (see Table 2). Consequently, the spark discharge was used as the norma: "pilot", partiy for convenience, but also because it was felt that it would cause less disturbance to the boundary layer and thermal plume above the sample surface.

With the exception of the two fire retarded polymers, the critica: mass flux at the firepoint appeared to be independent of the intensit: of the radiant flux in the range $12-35 \mathrm{~kW} / \mathrm{m}^{2}$. This was largely confirmer in a statistical analysis of the results, although the increase in "in" with heat flux for polypropylene and polystyrene was just significant a the $5 \%$ level.

The independence of $\dot{m}^{\prime \prime}$ on radiant flux for PMMA is in marker contrast to the observed dependence of the firepoint temperature at lor heat flux $\left(<1.7 \mathrm{~kW} / \mathrm{m}^{2}\right)$. Thomson and Drysdale (1) found $\mathrm{T}$ to be les: than $300^{\circ} \mathrm{C}$ at $14 \mathrm{kw} / \mathrm{m}^{2}$, which they attributed to a large increase in the effective surface area due to the formation of an open honeycomb structure as subsurface bubbles coalesced after the prolonged period of heating necessary to achieve the firepoint.

of the two fire-retarded polymers, FRPP could be ignited only a: the higher heat fluxes ( 25 and $33 \mathrm{~kW} / \mathrm{m}^{2}$ ): the flashpoint was not reachec at the lower heat fluxes even after prolonged exposure at the $1.9 \mathrm{~kW} / \mathrm{m}^{2}$. It was found that the critical mass flux was dependent on the radiant intensity, apparently decreasing with intensity. This dependency may bt due to progressive depletion of the fire retardant species. Thest results are presented in more detail elsewhere (14).

The "normal" polymers fall into two distinct groups, according te their composition. The hydrocarbon polymers (PE, PP and PS) have in" values of around $1 \mathrm{~g} / \mathrm{m}^{2} . \mathrm{s}$, while those for the oxygenated polymers (PMîf) and $\mathrm{POM}$ ) are approximately $2 \mathrm{~g} / \mathrm{m}^{2} . \mathrm{s}$. This is not unexpected as the stoichiometries for the combustion of the vapours are so different Taking the stoichiometric concentration for hydrocarbon vapour (HC) if air as $87 \mathrm{~g} / \mathrm{m}^{3}$ (15), and assuming that the pyrolysis products from PMM $t$ and POM are methyl methacrylate (MMA) and formaldehyde (F), respective1.y, the ratio of the stoichiometric concentrations (by mass) are 1.6 anc 2.2 for MMA/HC and F/HC respectively. Exact agreement could not bt expected, but the magnitude and direction of the trend are correct. However, on the same reasoning, the critical mass flux for PoM should b. greater than that for PMMA, which is contrary to the present results This will be discussed below.

Although the importance of critical mass flux as a criterion for ignition was first proposed by Bamford et al in 1946 ( 7 ), there have been very few attempts to measure it experimentally. Koohyar et al ( 8 ) report the measurement of " " for vertical slabs of different woods but the results are scattered over an order of magnitude. Melinek (16 subsequently analysed these data and quoted a mean value of $5.1 \mathrm{~g} / \mathrm{m}^{2} . \mathrm{s}$ The only experimental value available for horizontal samples is $2.2 \mathrm{~g} / \mathrm{m}^{2}$.s obtained by Mazhar (17) for white pine: although little confidence is placed in this value, it is consistent with the theoretical values deduced by Bamford et al. (7) $\left(2.5 \mathrm{~g} / \mathrm{m}^{2} . \mathrm{s}\right)$ and bs Atreya and Wichman (18) $\left(1.8 \mathrm{~g} / \mathrm{m}^{2} . \mathrm{s}\right)$. 


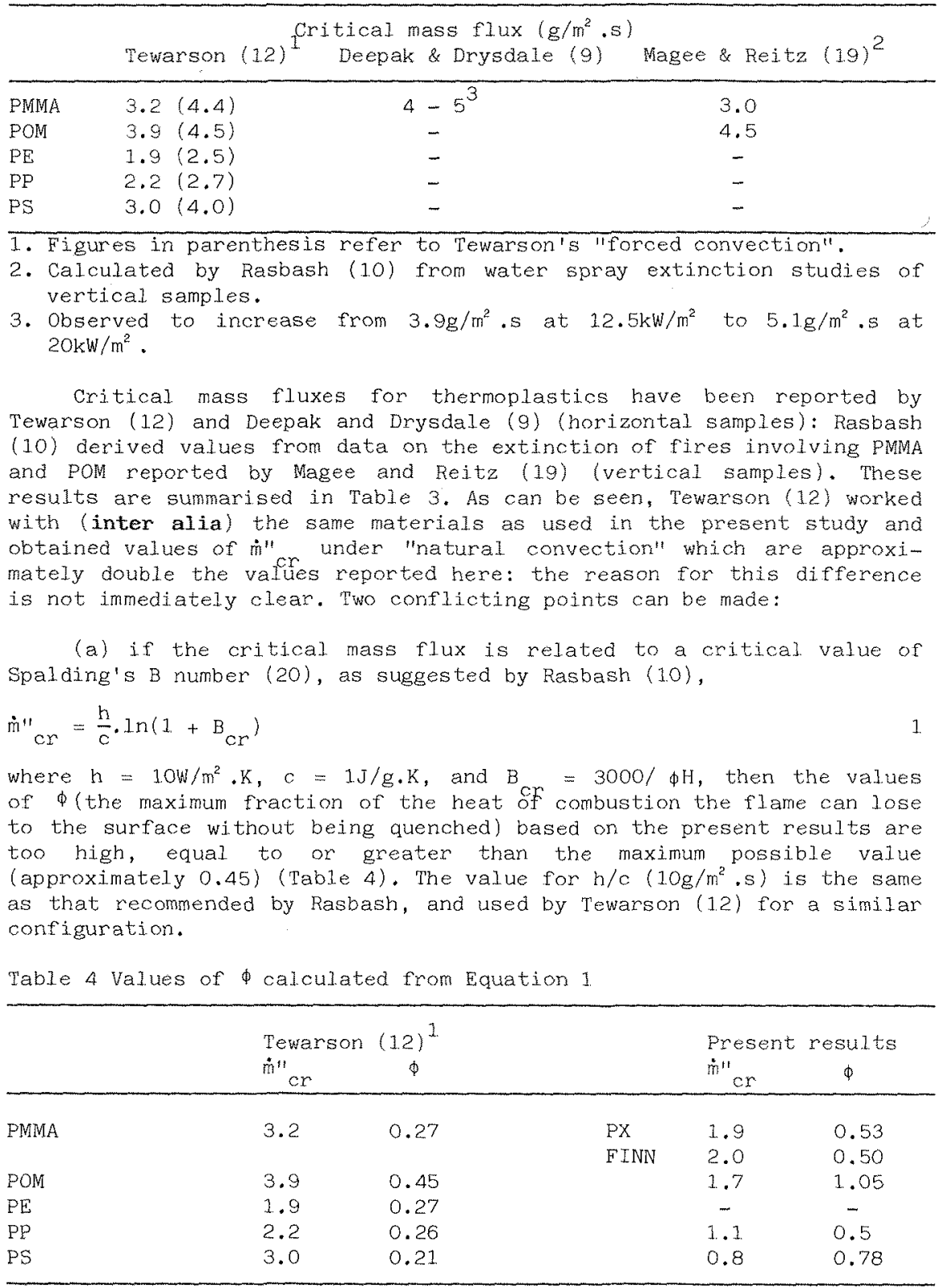

Tewarson's "natural convection".

(b) the present values of $\dot{m}^{\prime \prime}$ for PMMA and POM are similar to the value predicted for wood by Atreya and Wichman (18). Such agreement would seem logical on the basis that wood is also an "oxygenated polymer". It is worth noting that as the flammable constituents of the decomposition products are effectively diluted by carbon dioxide and 
water vapour, one might expect the critical mass flux for wood to be greater than that for PMMA or POM.

To resolve this uncertainty, it is necessary to establish if the measured flows of the volatiles are consistent with existing knowledge of the firepoints of flammable liquids. The limited data available indicate that the vapour pressure at the firepoint is super-stoichiometric. For example, Glassman and Dryer's data (21) indicate 1.3\% stoichiometric at the firepoint for n-decane, while Roberts and Quince (22) found higher figures, $1.6 x$ and $1.9 x$ stoichiometric for n-decane and n-dodecane respectively. To compare these figures with solid fuels, the concentration of fuel vapour above the surface of a solid fuel at its firepoint must be estimated from the appropriate value of $\dot{m}^{\prime \prime}$ : this requires knowledge of the flowrate of buoyant air at the surface. Unfortunately, this cannot be calculated as the behaviour of the boundary layer associated with a horizontal surface has not beer. analysed in a suitable fashion.

However, the relationship between the firepoint and the flashpoint should be considered. Zabetakis (15) has show that the ratio of the stoichiometric concentration to the lower limit concentration for $z$ range of flammable gases and vapours is approximately 1.8. If the flashpoint corresponds to the lower limit (e.g. see (4)), then the ratic $\dot{m}^{\prime \prime} / \dot{m}^{\prime \prime}$, should exceed 1.8 , and probably be greater than 2.3 , the value based on the vapour pressure data for n-decane, using Glassman anc Dryer's results (21). As can be seen in Table 2 , the ratio $\dot{m}^{\prime \prime} / \dot{m}^{\prime \prime}$ lies between 1.8 and 2.2 (except for the fire retarded plastics anc polystyrene), although these are likely to be underestimates as $\dot{m}^{\prime \prime} \mathrm{fl}$ refers to an "open cup" measurement rather than the "closed cup".

Rasbash's application of Spalding's B-number (10) to the firepoint condition must be considered further. Assuming that it is valid to use Equation 1 in this context, and that $\phi$ must be less than about 0.45 , one or more of the data used in the derivation of $\phi$ must be incorrect. Giver that the numerator of $B$ is, effectively, the "heat of combustion of air", and that $H$ is the heat of combustion of the volatiles, both of which are known with reasonable precision, it would seem that the uncertainty lies in the value selected for h/c. Rasbash (10) assumec that the average heat transfer coefficient (h) for heat losses by natural convection from a flat, horizontal plate would describe the situation adequately: Tewarson (12) confirmed the same figure $\left(10 \mathrm{~g} / \mathrm{m}^{2} . \mathrm{s}\right)$ experimentally (for "natural" convection), yet it is known that the local heat transfer coefficient varies from point to point across the surface. AI-Arabi and El-Riedy (23) found a significant variation of $r$ for horizontal plates (450mm square) maintained at $100^{\circ} \mathrm{C}$, in which the local value fell from around $1.0 \mathrm{~W} / \mathrm{m}^{2} . \mathrm{K}$ near the edge, passed through a minimum ( $4 \mathrm{~W} / \mathrm{m}^{2} . \mathrm{K}$ 30mm from the edge) and approached a value of $7 \mathrm{~W} / \mathrm{m}^{2} . \mathrm{h}$ towards the centre. In the present experiments, the surface approximatec to a horizontal plate, measuring $100 \mathrm{~mm} \times 120 \mathrm{~mm}$, although the air flov pattern close to the surface was influenced by the presence of the draught shield. It is possible that in the present experiments, the local heat transfer coefficient near the centre of the sample (plate) was considerably less than $10 \mathrm{~W} / \mathrm{m}^{2}$. K. If this were so, application of local value of $h$ would lead to much smaller values of than shown or Table 4 , and would be compatible with Rasbash's hypothesis.

There remains the question of the differences between the present results and those of Deepak and Drysdale (9) and of Tewarson (12). The experimental configurations in these two studies were similar, although 
the vertical tube surrounding the sample in Deepak's work was weter cooled. These experiments could not be repeated exactly, but instead the Supelux collar " "L" in Figure 1) was removed and the sample surrounded by a short length of a water-cooled cylinder (150mm in diameter), resting on the horizontai barrier shown as "G" in Eigure 1. Only a few experiments have been carried out, but these were sufficient to indicate that this configuration did indeed affect the values of $\dot{m}^{\prime \prime}$ : that for FINN was found to be increased by $30 \%$. This can be explained in terms of changes in the air flow pattern in the vicinity of the surface which would in turn affect the value of $h$. It would seem that the firepoint is very sensitive to the boundary conditions existing at the surface.

In view of this, it is clear that a greater understanding of the nature of the boundary layer associated with the sample configuration used in this work is required before the process of flame stabilisation at the firepoint can be understood in detail.

\section{CONCLUSIONS}

The critical flowrate of fuel volatiles from horizontal samples of eight thermoplastics have been determined. It has been shown that the values derived are sensitive to the boundary layer conditions existing at the surface. It will be necessary to derive accurate values for the convective heat transfer coefficient at the surface to enable the ignition condition to be analysed in detail.

\section{ACKNOWLEDGEMENTS}

The authors are most grateful to the Home office for their continuing support for this project.

\section{REFERENCES}

1. H.E. Thomson and D.D. Drysdale, "Flammability of plastics. I. Ignition temperatures." Fire and Materials, 11 163-172 (1987).

2. A.M. Kanury, "Ignition of cellulosic materials: a review." Fire Research Abstracts and Reviews, 14 24-52 (1972).

3. H.E. Mittler, "The Harvard fire model." Fire Safety Journal. 9 7-1.6 (1985)

4. D.D. Drysdale, "Introduction to Fire Dynamics." John wiley, Chichester, 1985).

5. J.R. Hallman, J.R. Welker, and C.M. Sliepcevich, "Ignition of polymers". SPE Journal, 28 43-47 (1972).

6. International standards Organisation. Fire Tests - Reaction to Fire - Ignitability of Building Products. ISO/TC92/SCI/WG2-N54 (1984).

7. C.H. Bamford, J. Crank and D.H. Malan, "The combustion of wood." Proc. Cambrdige Phil. Soc., 42 1.66-182 (1946).

8. A.N. Koohyar, J.R. Welker and C.M. Sliepcevich, "The irradiation and ignition of wood by flame." Fire Technology 4 284-291 (1968).

9. D. Deepak and D.D. Drysdale, "Flammability of solids: an apparatus to measure the critical mass flux at the firepoint." Fire Safety Journal 5 167-169 (1983).

10. D.J. Rasbash, "Relevance of firepoint theory to the assessment of fire behaviour of combustible materials", International Symposium on Fire Safety of Combustible Materials, (Edinburgh University, 1975) p. 169 . 
11. D.J. Rasbash, D.D. Drysdale and D. Deepak, "Critical heat and mass transfer at pilot ignition and extinction of a material." Fire Safety Journal, $101-10$ (1986).

12. A. Tewarson, "Experimental evaluation of flammability parameters of polymeric materials." in "Flame Retardant Polymeric Materials, Volume 3." Eds. M. Lewin, S.M. Atlas and E.M. Pearce (Plenum Press, New York and London, 1982) pp.97-153.

13. Standard Test Method for Flashooint and Firepoint by the Cleveland Open Cup Test Method. D92-78. American Society for Testing and Materials, Philadelphia (1978).

14. H.E. Thonson and D.D. Drysdale, "Flammability of Plastics II. Critical Mass Flux at the Firepoint" in preparation.

15. M.G. Zabetekis, "Flammability Characteristics of Combustible Gases and Vapours." US Bureau of Mines, Bulletin 627 (1965).

16. S. Melinek, Fire Research Note 755 (1969).

17. A.A. Mazhar, University of Edinburgh, unpublished results.

18. A. Atreya and I.S. Wichman, "Heat and mass transfer during piloted ignition of cellulosic solids", Second ASME-JSME Thermal Engineering Joint Conference, Honolulu 1987.

19. R.S. Magee and R.D. Reitz, 15th Symposium (International) on Combustion (Combustion Institute, Pittsburgh, PA) p.337.

20. D.B. Spalding, "Some Fundamentals of Combustion". (Butterworths, London, 1956).

21. I. Glassman and F. Dryer, "Flame spreading across liquid fuels." Fire Safety Journal, 3 1.23-138 (1980/1981).

22. A.F. Roberts and B.F. Quince, "A limiting condition for the burning of flammable liquids." Combustion and Flame $20245-251$ (1973).

23. M. AI-Arabi and M.K. El-Riedy, "Natural convection heat transfer from isothermal horizontal plates of different shapes", Interm nationaI J. Heat and Mass Transfer, 191399 (1976).

\section{LIST OF SYMBOLS}

$B$ Critical value of Spalding's B-number (-)

$c^{c r}$ Specific heat of air $(\mathrm{kJ} / \mathrm{g} . \mathrm{K})$

h Convective heat transfer coefficient ( $\left.W / \mathrm{m}^{2} . K\right)$

$\dot{m}$ " Critical mass flux at the firepoint $\left(\mathrm{g} / \mathrm{m}^{2} . \mathrm{s}\right)$

$\dot{m}^{\prime \prime}$ cr Critical mass $f l u x$ at the flashpoint $\left(\mathrm{g} / \mathrm{m}^{2}\right.$.s)

$t$ fl Time to ignition(s)

$\mathrm{T}$ ig Firepoint temperature $\left({ }^{\circ} \mathrm{C}\right)$

Greek Symbols

$\mathrm{H}$ Heat of combustion of the volatiles $(\mathrm{kJ} / \mathrm{g})$

$\phi$ Maximum fraction of the heat of combustion that a nascent flame can lose to the surface without extinguishing. 